\title{
Rates and Correlates of Potentially Inappropriate Colorectal Cancer Screening in the Veterans Health Administration
}

\author{
Adam A. Powell, PhD, MBA ${ }^{7,2,8}$, Sameer D. Saini, MD, MS ${ }^{3,4}$, Matthew K. Breitenstein, PhD, MS ${ }^{1,5}$, \\ Siamak Noorbaloochi, $P h D^{1,2}$, Andrea Cutting, $M A^{7}$, Deborah A. Fisher, $M D, M H S^{6,7}$, \\ Hanna E. Bloomfield, MD, MPH ${ }^{1,2}$, Krysten Halek, MA ${ }^{7}$, and Melissa R. Partin, PhD ${ }^{1,2}$
}

\begin{abstract}
'Center for Chronic Disease Outcomes Research (CCDOR), Minneapolis VA Health Care System, Minneapolis, MN, USA; ${ }^{2}$ Department of Medicine, University of Minnesota, Minneapolis, MN, USA; ${ }^{2}$ Veterans Affairs Center for Clinical Management Research, VA Ann Arbor Healthcare System, Ann Arbor, MI, USA; ${ }^{4}$ Division of Gastroenterology, University of Michigan Medical School, Ann Arbor, MI, USA; ${ }^{5}$ Institute for Health Informatics, University of Minnesota, Minneapolis, MN, USA; 'Health Services Research and Development Center of Excellence in Primary Care, Durham VA Medical Center, Durham, NC, USA; ${ }^{7}$ Department of Medicine, Duke University Medical Center, Durham, NC, USA; ${ }^{8}$ Minneapolis VA Health Care System,

Minneapolis, MN, USA.
\end{abstract}

BACKGROUND: Inappropriate use of colorectal cancer (CRC) screening procedures can inflate healthcare costs and increase medical risk. Little is known about the prevalence or causes of inappropriate CRC screening.

OBJECTIVE: Our aim was to estimate the prevalence of potentially inappropriate CRC screening, and its association with patient and facility characteristics in the Veterans Health Administration (VHA) .

DESIGN AND PARTICIPANTS: We conducted a crosssectional study of all VHA patients aged 50 years and older who completed a fecal occult blood test (FOBT) or a screening colonoscopy between 1 October 2009 and 31 December 2011 ( $n=1,083,965)$.

MAIN MEASURES: Measures included: proportion of patients whose test was classified as potentially inappropriate; associations between potentially inappropriate screening and patient demographic and health characteristics, facility complexity, CRC screening rates, dependence on FOBT, and CRC clinical reminder attributes.

KEY RESULTS: Of 901,292 FOBT cases, 26.1\% were potentially inappropriate (13.9\% not due, $7.8 \%$ limited life expectancy, $11.0 \%$ receiving FOBT when colonoscopy was indicated). Of 134,335 screening colonoscopies, $14.2 \%$ were potentially inappropriate $(10.4 \%$ not due, $4.4 \%$ limited life expectancy). Each additional 10 years of patient age was associated with an increased likelihood of undergoing potentially inappropriate screening (ORs $=1.60$ to 1.83 depending on screening mode). Compared to facilities scoring in the bottom third on a measure of reliance on FOBT (versus screening colonoscopy), facilities scoring in the top third were less likely to conduct potentially inappropriate FOBTs $(\mathrm{OR}=0 ., 78)$ but more likely to conduct potentially inappropriate colonoscopies $(\mathrm{OR}=2.20)$. Potentially inappropriate colonoscopies were less likely to be conducted at facilities where primary care providers were assigned partial responsibility $(\mathrm{OR}=0.74)$ or full responsibility $(\mathrm{OR}=0.73$ ) for completing the $\mathrm{CRC}$ clinical reminder.

Received July 14, 2014

Revised December 1, 2014

Accepted December 12, 2014

Published online January 21, 2015
CONCLUSIONS: A substantial number of VHA CRC screening tests are potentially inappropriate. Establishing processes that enforce appropriate screening intervals, triage patients with limited life expectancies, and discourage the use of FOBTs when a colonoscopy is indicated may reduce inappropriate testing.

KEY WORDS: colorectal cancer; screening; utilization; practice variation; Veterans.

$\mathrm{J}$ Gen Intern Med 30(6):732-41

DOI: $10.1007 / \mathrm{s} 11606-014-3163-8$

(c) Society of General Internal Medicine 2015

I n 2014, an estimated 136,830 Americans will be diagnosed with colorectal cancer (CRC), ${ }^{1}$ and an estimated 50,310 will die of the disease. ${ }^{1}$ Appropriately applied, routine screening can reduce both CRC incidence and mortality. ${ }^{2}$ Thus, many health organizations, including the Veterans Health Administration (VHA), have invested heavily in programs to increase CRC screening. Clinical reminder systems are now commonly used to alert providers at the point of care when patients are due for screening. CRC screening performance measures are now included in most quality measurement systems. In the VHA, CRC screening rates are used as one measure of the quality of care provided by physicians, clinics and facilities, and can affect clinician and administrator compensation plans. As a result, the VHA CRC screening rate of $80 \%^{3}$ is well above US general population rates. ${ }^{4}$

One potential unintended consequence of the emphasis on screening promotion is the inappropriate use of screening tests. There are at least three reasons a CRC screening test could be clinically inappropriate. First, the patient may not be due for screening. The US Preventive Services Task Force recommends screening with fecal occult blood tests (FOBTs) annually, with colonoscopy every 10 years, or with flexible sigmoidoscopy every 5 years. ${ }^{5}$ Second, the patient may be unlikely to live long enough to realize a screening benefit. 
Decision analyses and a meta-analysis of randomized controlled trial (RCT) data suggest that average-risk individuals with a life expectancy of less than 10 years are unlikely to benefit from CRC screening. ${ }^{6,7}$ Third, the patient may receive the wrong test. Generally, patients with CRC-related symptoms or with a personal or family history of CRC should undergo colonoscopy (not FOBT or other tests). ${ }^{8}$ Screening patients who are not yet due or who are of limited life expectancy can strain gastroenterology and laboratory resources and expose patients to unnecessary inconvenience, stress, and medical risk. Serious complications are estimated to occur in 25 per 10,000 colonoscopy procedures, ${ }^{9}$ and deaths attributable to colonoscopy occur in three per 10,000 procedures. ${ }^{10}$ These forms of inappropriate screening can result in harm even when FOBTs are used because, if the FOBT is positive, the patient may undergo a diagnostic colonoscopy. Utilizing FOBTs when a colonoscopy is indicated may delay or decrease the likelihood of undergoing a needed colonoscopy, potentially decreasing the benefits of screening.

Previous studies of inappropriate CRC screening ${ }^{11-14}$ assessed only one facility, one screening mode, or one category of inappropriate screening. The current study quantifies the extent of potentially inappropriate screening for both FOBT and colonoscopy in the entire VHA system (130 medical facilities), using a measure that distinguishes between three types of inappropriate screening (not due, limited life expectancy, and wrong test), and examines the association between this measure and patient and facility attributes.

\section{METHODS}

\section{Sample Identification}

We searched VHA databases containing extracted medical record information on all VHA patients to identify data on all colonoscopies and outpatient fecal occult blood tests (FOBTs) performed or paid for by VHA between 1 October 2009 and 31 December 2011 on patients aged 50 years and older. We did not include flexible sigmoidoscopy, since this mode represents fewer than $2 \%$ of CRC testing procedures. Among patients with two or more CRC tests, the first was used (referred to hereafter as the index test).

\section{Dependent Measures}

To identify potentially inappropriate tests, we extracted patient age, diagnosis codes associated with gastrointestinal (GI) or life-limiting conditions, and dates of all colonoscopies, FOBTs, flexible sigmoidoscopies and barium enemas occurring within 10 years of the index test. We also obtained the FOBT result.

Cases were classified as "potentially inappropriate - not due" if there was a completed FOBT within the prior 10 months of the index test date, colonoscopy within 9.5 years, or sigmoidoscopy or barium enema within 4.5 years. These time intervals have been used in prior research ${ }^{15}$ and are slightly shorter than intervals recommended in national guidelines. ${ }^{5}$ This allows for early screening that may occur due to scheduling convenience.

For each patient, we calculated a Charlson-Deyo comorbidity score, ${ }^{16,17}$ an estimate of disease burden that predicts $\mathrm{CRC}^{18}$ and all-cause mortality. ${ }^{19}$ Patients were classified as "potentially inappropriate-limited life expectancy" if their Charlson-Deyo Comorbidity score was four or greater, if there was documentation of life expectancy less than 1 year, or if over the age of 85 years. The Charlson-Deyo cutoff of four has been used to define severe life-limiting comorbidities in prior cancer screening studies. ${ }^{20,21}$ The age criterion is based on the US Preventive Services Task Force recommendation against screening patients over the age of 85 years. ${ }^{22}$

Cases were classified as "potentially inappropriate — wrong test" if the index test was an FOBT and the patient had documentation of a recent gastrointestinal condition that was considered an indication for colonoscopy (see Appendix 1), a personal/family history of CRC, or a prior positive FOBT and no follow-up colonoscopy.

\section{Independent Measures}

Patient variables examined included: gender, age, race, ethnicity, and marital status. These variables have been associated with CRC screening in prior research. ${ }^{23-25}$

We hypothesized that facility $\mathrm{CRC}$ screening rate (percent of patients screened), dependence on FOBT versus screening colonoscopy, and complexity (a standardized score composed of workload volume, patient risk level, number of complex clinical services offered, and amount of teaching and research activity that represents complexity of services and activities) ${ }^{26}$ would correlate with potentially inappropriate screening, because these variables are likely to be associated with the number and types of processes in place to facilitate screening. To test these hypotheses, we calculated the proportion of index tests that were FOBTs, and obtained 2010 CRC screening rates and complexity scores (derived from 2009 to 2010 data). To compare relatively low, moderate, and high scores, facilities were split into three equal groups on these measures.

All VHA primary care clinics utilize a CRC screening clinical reminder (CR) that is programmed locally. We hypothesized that attributes of these CRs would be associated with potentially inappropriate screening because these attributes affect which staff members discuss CRC screening with patients, the information that is discussed, and the ability of providers to exclude patients from future screening. To obtain CR attributes, we contacted a computer application programmer at each facility and obtained screenshots and programming language of CRs from 104 of 130 facilities. These materials were coded to capture key $\mathrm{CR}$ attributes. 


\section{Identification of Screening Colonoscopies}

To distinguish screening from non-screening colonoscopies, three investigators manually reviewed charts of a random set of 754 colonoscopy cases. Cases in which providers entered the term "screening" or "Sx" as a procedure indication and did not list accompanying symptoms or additional indications were classified as screening (391 cases). All other indications were classified as non-screening (351 cases). We excluded 12 cases because indication was undocumented. A random 41 cases reviewed by two reviewers resulted in two disagreements (Agreement $=0.95$, Cohen's kappa $=0.90$ ). Disagreements were resolved through discussion. A two-step algorithm was then developed to classify all colonoscopies as screening or non-screening. In Step 1, we classified as non-screening all chart-reviewed colonoscopies with a CRC-related diagnosis code entered between 0 and 365 days of the procedure. This set of codes (Appendix 2, Step 1) has been used previously to identify non-screening colonoscopies. ${ }^{27,28}$ In Step 2, we developed a Random Forest model to classify cases not classified as non-screening in Step 1. (See Appendix 2, Step 2 for a list of variables used.) The Random Forest method uses regression trees and random selection of predictor variables and cases to avoid high-dimensionality. This two-step classification process correctly classified $88 \%$ of chart-reviewed screening cases and $100 \%$ of chart-reviewed non-screening cases. We then applied this classification process to colonoscopy cases in the full data set. Our final sample included 901,292 FOBT and 134,335 colonoscopy cases classified as screening. We excluded 272,352 colonoscopies classified as non-screening.

\section{Analyses}

We report the percent of tests classified as potentially inappropriate by screening mode (colonoscopy, FOBT) and by the reason for designation (not due, limited life expectancy, or wrong test). The percent of potentially inappropriate tests is further broken out by patient and facility characteristics in Appendices 3 and 4. Among potentially inappropriate FOBT cases, we report the percent of cases with a positive test result.

We used hierarchical logistic regression models to assess the relationship between each independent variable and potentially inappropriate screening, adjusting for clustering of patients within facilities. Models were created to assess independent variables by each mode (FOBT or colonoscopy) and by each reason (any reason, not due, limited life expectancy, wrong test). For each dependent variable, we created a single model, entering all patient characteristics. Because many of the facility characteristics were highly correlated, we then estimated the effect of each facility characteristic, controlling for patient characteristics. A dummy code was created for each independent variable to represent missing data. (For parsimony, odds ratios for missing data categories are not reported.) All statistical analyses were performed using SAS 9.2 (SAS Institute Inc, Cary, North Carolina).

\section{RESULTS}

\section{Sample Characteristics}

Characteristics of patients and facilities are reported in Tables 1 and 2. FOBT and screening colonoscopy patients were similar, although FOBT patients were older $\left(\mathrm{Mean}_{\mathrm{FOBT}}=64.7\right.$ years, $\mathrm{Mean}_{\text {Colonoscopy }}=61.0$ years $)$. Patients were primarily white $(80.3 \%)$ and male $(95.1 \%)$. Facility CRC screening rates were high across all sites, ranging from 71 to $93 \%$. FOBT was the predominant screening mode. Only a small number of sites had CRs that included questions about the patient's family CRC history $(8.7 \%)$. All other CR characteristics were present in at least $18 \%$ of facilities.

\section{Rates of Potentially Inappropriate Screening}

In all, $24.5 \%$ of cases were classified as potentially inappropriate $(26.1 \%$ of FOBTs and $14.2 \%$ of colonoscopies - see Table 3). Patients could be categorized as potentially inappropriate for multiple reasons. Among both FOBT and colonoscopy groups, "patient not yet due" was the most common reason for being designated as potentially inappropriate (13.9 and $10.4 \%$ respectively). Time since prior colonoscopy was the predominant reason cases were not due. Sensitivity analysis using a more restrictive definition of "not due" (9 months for FOBT, 9 years for colonoscopy, and 4 years for sigmoidoscopy/barium enema) reduced the number of "not due" cases by $1 \%$. Limited life expectancy accounted for $7.3 \%$ of potentially inappropriate tests. A total of $11.0 \%$ of FOBTs were classified as potentially inappropriate because a colonoscopy appeared to be indicated instead of a FOBT.

FOBT positivity rates were $13 \%$ among "not due" patients, $16 \%$ among "limited life expectancy" patients, and $19 \%$ among patients indicated for colonoscopy.

Table 1. Patient Characteristics by Mode of Screening (Percent or Mean and Standard Deviation of Patient Cohort)

\begin{tabular}{|c|c|c|c|}
\hline & Total & FOBT & $\begin{array}{l}\text { Screening } \\
\text { Colonoscopy }\end{array}$ \\
\hline $\mathrm{N}$ & $1,035,627$ & 901,292 & 134,335 \\
\hline $\begin{array}{l}\text { Age - Mean } \\
\quad \text { (Standard Deviation) }\end{array}$ & $64.2(8.6)$ & $\begin{array}{l}64.7 \\
(8.7)\end{array}$ & $61.0(6.9)$ \\
\hline $\begin{array}{l}\text { Gender Male } \\
\text { Race }\end{array}$ & $95.1 \%$ & $95.1 \%$ & $95.3 \%$ \\
\hline White & 80.3 & 80.8 & 77.3 \\
\hline African American & 17.4 & 17.0 & 20.1 \\
\hline $\begin{array}{l}\text { American Indian/Alaskan } \\
\text { Native }\end{array}$ & 1.7 & 1.6 & 1.9 \\
\hline Asian/Pacific Islander & 0.6 & 0.6 & 0.7 \\
\hline $\begin{array}{l}\text { Ethnicity - Hispanic/Latino } \\
\text { Marital status }\end{array}$ & 6.7 & 6.9 & 5.9 \\
\hline Married & 55.5 & 55.9 & 52.4 \\
\hline Single - Never Married & 9.1 & 8.9 & 10.5 \\
\hline Divorced/Separated & 30.0 & 29.6 & 33.3 \\
\hline Widowed & 5.4 & 5.6 & 3.8 \\
\hline
\end{tabular}


Table 2. Facility Characteristics (Percent of Facilities and Number of Facilities for which Data Was Obtained

\begin{tabular}{|c|c|c|}
\hline & Percent & Facility $\mathbf{N}$ \\
\hline \multicolumn{3}{|l|}{ (Range of patients per facility: 891 to 29,766 ) } \\
\hline Standardized Complexity Score & & 128 \\
\hline Lower third & 32.8 & \\
\hline Middle third & 34.4 & \\
\hline Upper third & 32.8 & \\
\hline $\begin{array}{l}\text { CRC Screening Performance Score (Range } 71 \\
\text { to } 93 \% \text { ) }\end{array}$ & & 129 \\
\hline$<80 \%$ & 34.9 & \\
\hline 80 to $84 \%$ & 34.9 & \\
\hline$>84 \%$ & 30.2 & \\
\hline $\begin{array}{l}\text { Percent screening completed with FOBT } \\
\text { (Range } 18.6 \text { to } 99.6 \% \text { ) }\end{array}$ & & 130 \\
\hline$<82 \%$ & 33.8 & \\
\hline 82 to $91 \%$ & 32.3 & \\
\hline$>91 \%$ & 33.8 & \\
\hline CR completion instructions promote: & & 41 \\
\hline Colonoscopy over FOBT & 14.7 & \\
\hline FOBT over colonoscopy & 85.3 & \\
\hline $\begin{array}{l}\text { CR asks provider to enter elements of patient's } \\
\text { family history }\end{array}$ & 8.7 & 104 \\
\hline CR can be turned off by provider & 22.1 & 104 \\
\hline $\begin{array}{l}\text { CR allows provider to specify timing of next } \\
\text { colonoscopy }\end{array}$ & 21.4 & 103 \\
\hline $\begin{array}{l}\text { CR contains a general 'not indicated' option } \\
\text { (no further input required) }\end{array}$ & 47.1 & 104 \\
\hline $\begin{array}{l}\text { CR includes patient screening decision } \\
\text { education }\end{array}$ & 18.3 & 104 \\
\hline CR completion assigned to: & & 76 \\
\hline Intake Nurse Only & 25.0 & \\
\hline Primary Care Provider Only & 31.6 & \\
\hline Both Primary Care Provider \& Nurse & 43.4 & \\
\hline
\end{tabular}

CRC Colorectal cancer; CR Clinical reminder; FOBT Fecal occult blood test

\section{Characteristics Associated with Potentially Inappropriate Screening}

Associations between potentially inappropriate screening and patient and facility characteristics are reported in Tables 4 and 5. Each additional 10 years of patient age was associated with an $83 \%$ increased likelihood of potentially inappropriate screening among FOBT patients and $60 \%$ increased likelihood among colonoscopy patients (all $p<0.001$ ). This relationship between age and potentially inappropriate screening was consistent across all reasons. Potentially inappropriate FOBTs were less common among males than females $(\mathrm{OR}=0.75, p<0.001)$, primarily because males were less likely to complete an FOBT before due $(\mathrm{OR}=0.77, p<0.001)$ or to receive the wrong test $(\mathrm{OR}=0.68, p<0.001)$. Male colonoscopy recipients, however, were more likely than females to be of limited life expectancy $(\mathrm{OR}=1.49, p<0.001)$. African Americans were more likely than Whites to complete a potentially inappropriate test $\left(\mathrm{OR}_{\mathrm{FOBT}}=1.47, \mathrm{OR}_{\text {colonoscopy }}=1.20\right.$, all $p<0.001$ ), with limited life expectancy contributing most to this association $\left(\mathrm{OR}_{\mathrm{FOBT}}=1.72, \mathrm{OR}_{\text {colonoscopy }}=1.69\right.$, all $p<0.001)$. Hispanic and unmarried statuses were significantly positively associated with potentially inappropriate screening for any reason; however, these effects were small.

Compared to low-complexity facilities, screening colonoscopies conducted at high-complexity facilities were more likely to be classified as "potentially inappropriate-limited life expectancy" ( $\mathrm{OR}=1.37, p<0.001)$. Facilities with CRC screening rates in the upper third were more likely than those scoring in the lower third to conduct colonoscopies before patients were due for screening $(\mathrm{OR}=1.34, p=0.03)$. Facilities in the top third on our measure of relative use of FOBT were less likely to conduct potentially inappropriate FOBTs $(\mathrm{OR}=0.78$, $p=0.003$ ), but more likely to conduct potentially inappropriate colonoscopies $(\mathrm{OR}=2.20, p<0.001)$ compared to facilities scoring in the bottom third. This relationship between FOBT use and potentially inappropriate screening was consistent across all reasons. Facilities that assigned primary care providers partial or full responsibility for completing the CR were less likely to conduct potentially inappropriate screening colonoscopies for any reason than facilities that assigned sole responsibility for completing the $\mathrm{CR}$ to intake nurses $(\mathrm{OR}=0.73$ to 0.74 , $\mathrm{p}$ 's $=0.04)$, but no other $\mathrm{CR}$ attributes were

Table 3. Percent of Screened Patients Who Were Classified as Having Received Potentially Inappropriate Screening by Screening Mode and Reason Test Was Potentially Inappropriate (Patients Could Be Classified as Potentially Inappropriate for Multiple Reasons)

\begin{tabular}{|c|c|c|c|}
\hline & $\begin{array}{l}\text { Percent of } 1,035,627 \\
\text { total cases }\end{array}$ & $\begin{array}{l}\text { Percent of 901,292 } \\
\text { FOBT cases }\end{array}$ & $\begin{array}{l}\text { Percent of } 134,335 \text { screening } \\
\text { colonoscopy cases }\end{array}$ \\
\hline Inappropriate test for any reason & 24.5 & 26.1 & 14.2 \\
\hline Patient not due for screening & 13.5 & 13.9 & 10.4 \\
\hline Within 10 months of prior FOBT & 2.1 & 1.9 & 4.0 \\
\hline Within 9.5 years of prior colonoscopy & 11.4 & 12.4 & 4.6 \\
\hline Within 4.5 years of prior sigmoidoscopy or barium enema & 0.3 & 0.0 & 2.2 \\
\hline Limited life expectancy & 7.3 & 7.8 & 4.4 \\
\hline Charlson score of 4 or more & 5.3 & 5.5 & 3.8 \\
\hline Patient age $85+$ & 1.6 & 1.8 & 0.2 \\
\hline Palliative care & 0.3 & 0.3 & 0.1 \\
\hline Life expectancy estimate $<1$ year & 0.6 & 0.7 & 0.4 \\
\hline FOBT done when diagnostic or surveillance colonoscopy indicated & 9.6 & 11.0 & - \\
\hline Gastrointestinal symptoms & 5.2 & 5.9 & - \\
\hline Personal history of CRC & 0.7 & 0.8 & - \\
\hline Family history of CRC & 1.4 & 1.6 & - \\
\hline Prior positive FOBT and no follow-up colonoscopy & 3.0 & 3.5 & - \\
\hline
\end{tabular}

CRC Colorectal cancer; FOBT Fecal occult blood test 
Table 4. Association Between Patient Characteristics and Receipt of a Potentially Inappropriate FOBT or Screening Colonoscopy by Reason Type*

\begin{tabular}{|c|c|c|c|c|}
\hline & $\begin{array}{l}\text { Any Reason OR } \\
(95 \% \text { CI) }\end{array}$ & $\begin{array}{l}\text { Not Due OR } \\
(95 \% \text { CI) }\end{array}$ & $\begin{array}{l}\text { Limited Life Expectancy } \\
\text { OR (95\% CI) }\end{array}$ & $\begin{array}{l}\text { Wrong Test OR } \\
(95 \% \mathrm{CI})\end{array}$ \\
\hline \multicolumn{5}{|l|}{ FOBT } \\
\hline Age (per additional 10 years) & $1.83(1.82,1.84)$ & $1.36(1.35,1.37)$ & $2.84(2.82,2.87)$ & $1.66(1.65,1.67)$ \\
\hline \multirow{2}{*}{\multicolumn{5}{|c|}{ Race (vs. White) }} \\
\hline & & & & \\
\hline African American & $1.47(1.44,1.49)$ & $1.29(1.27,1.32)$ & $1.72(1.68,1.76)$ & $1.44(1.41,1.47)$ \\
\hline American Indian & $1.14(1.10,1.19)$ & $1.09(1.04,1.15)$ & $1.18(1.10,1.26)$ & $1.07(1.01,1.13)$ \\
\hline Asian & $1.06(0.99,1.14)$ & $1.01(0.93,1.11)$ & $1.02(0.90,1.16)$ & $1.05(0.94,1.17)$ \\
\hline Ethnicity - Hispanic & $1.12(1.10,1.15)$ & $1.10(1.07,1.14)$ & $1.19(1.14,1.24)$ & $1.07(1.03,1.11)$ \\
\hline \multicolumn{5}{|l|}{ Marital Status (vs. married) } \\
\hline Divorced/Separated & $1.09(1.08,1.10)$ & $1.09(1.07,1.10)$ & $1.18(1.15,1.20)$ & $1.04(1.02,1.05)$ \\
\hline Widowed & $1.18(1.16,1.21)$ & $0.99(0.97,1.02)$ & $1.41(1.38,1.45)$ & $1.11(1.08,1.14)$ \\
\hline \multicolumn{5}{|l|}{ COLONOSCOPY } \\
\hline Age (per additional 10 years) & $1.60(1.57,1.64)$ & $1.44(1.40,1.48)$ & $1.86(1.79,1.93)$ & \\
\hline Gender - Male & $1.12(1.03,1.21)$ & $1.02(0.93,1.12)$ & $1.49(1.27,1.75)$ & \\
\hline \multicolumn{5}{|l|}{ Race (vs. White) } \\
\hline African American & $1.20(1.15,1.26)$ & $1.02(0.97,1.08)$ & $1.69(1.58,1.81)$ & \\
\hline American Indian & $1.08(0.95,1.22)$ & $1.05(0.91,1.21)$ & $1.14(0.93,1.41)$ & \\
\hline Asian & $1.01(0.81,1.27)$ & $1.15(0.90,1.47)$ & $0.66(0.42,1.04)$ & \\
\hline Ethnicity - Hispanic & $1.08(1.01,1.17)$ & $1.03(0.94,1.12)$ & $1.23(1.09,1.39)$ & \\
\hline \multicolumn{5}{|l|}{ Marital Status (vs. married) } \\
\hline Single & $1.19(1.13,1.26)$ & $1.04(0.97,1.11)$ & $1.53(1.41,1.67)$ & \\
\hline Divorced/Separated & $1.11(1.07,1.15)$ & $1.05(1.00,1.09)$ & $1.26(1.19,1.34)$ & \\
\hline Widowed & $1.17(1.09,1.27)$ & $1.04(0.95,1.14)$ & $1.45(1.29,1.63)$ & \\
\hline
\end{tabular}

FOBT Fecal occult blood test

* Odds ratio (95\% confidence interval) adjusted for clustering of patients within facilities-all patient-level independent variables entered simultaneously into each model

significantly associated with overall rates of potentially inappropriate screening.

\section{DISCUSSION}

In a cohort of over one million VHA patients receiving CRC screening, we categorized $26 \%$ of FOBT cases and $14 \%$ of screening colonoscopy cases as potentially inappropriate. These estimates amount to approximately 104,600 potentially inappropriate FOBTs and 8,500 potentially inappropriate screening colonoscopies annually in the VHA. In addition, our results suggest that approximately 7,200 patients who are not yet due for screening and 5,000 patients with limited life expectancies have positive FOBTs, which could lead to over 12,000 additional colonoscopies annually.

All inappropriate screening tests waste screening resources. Additional negative effects may occur, depending on the screening mode, result of the test, and the reason the test was inappropriate. For example, FOBTs that are conducted before a patient is due compress the time interval between screening tests and therefore increase the lifetime risk of a false positive test. This in turn exposes patients to additional risk of complications from unnecessary diagnostic colonoscopies. Patients with limited life expectancies that complete screening tests expose themselves to the risk of being diagnosed and treated for cancer even when that cancer may have never caused morbidity. FOBTs that are conducted when a colonoscopy is indicated not only waste lab and primary care staff resources, but also increase the risk of delayed or missed cancer diagnoses.

Rates of potentially inappropriate screening in our sample are comparable, and in some cases lower, than those found in other studies. A VHA study examining FOBT overuse in 24 facilities between 2004 and 2009 reported that $21 \%$ of FOBTs were completed too soon after a prior screening test ${ }^{15}$ (compared to $14 \%$ observed in > 100 VHA facilities between 2009 and 2011 in our study). A large-scale review of screening colonoscopies conducted in 11 countries classified $14 \%$ of procedures as inappropriate, ${ }^{29}$ which is equivalent to the proportion we report, but two US studies examining the appropriateness of colonoscopy referrals (both screening and nonscreening) classified 19 to $28 \%$ as inappropriate. ${ }^{30,31}$ Two single-site VHA reviews of patients with a positive FOBT in 1999 and 2004 found that 35 to $41 \%$ of these patients should either have received a colonoscopy instead of FOBT or should not have been screened at all ${ }^{11,12}$ (compared to $26 \%$ classified as potentially inappropriate for any reason in our more recent nationally representative VHA sample). Another VHA study using data collected from four facilities between 2001 and 2002 found that $41 \%$ of patients with a life expectancy of 5 years or less completed a CRC screening test ${ }^{21}$ (compared to $7 \%$ classified as limited life expectancy in our nationally representative study using more recent data and a more conservative definition of limited life expectancy). Differences in estimates across studies may be due to temporal and regional variation in inappropriate screening rates, or variation in methodology and definitions of inappropriate screening. 
Table 5. Association Between Facility Characteristics and Receipt of a Potentially Inappropriate FOBT or Screening Colonoscopy by Reason Type, Controlling for Patient Characteristics*

\begin{tabular}{|c|c|c|c|c|}
\hline & $\begin{array}{l}\text { Any Reason OR } \\
(95 \% \text { CI })\end{array}$ & $\begin{array}{l}\text { Not Due OR } \\
(95 \% \mathrm{CI})\end{array}$ & $\begin{array}{l}\text { Limited Life Expectancy } \\
\text { OR (95\% CI) }\end{array}$ & $\begin{array}{l}\text { Wrong Test OR } \\
(95 \% \text { CI) }\end{array}$ \\
\hline \multicolumn{5}{|l|}{ FOBT } \\
\hline \multicolumn{5}{|l|}{ Complexity score (vs. lower third) } \\
\hline Middle third & $0.95(0.80,1.12)$ & $0.92(0.72,1.17)$ & $1.04(0.95,1.14)$ & $0.97(0.84,1.11)$ \\
\hline \multirow{2}{*}{\multicolumn{5}{|c|}{ CRC screening performance score (vs. lower third) }} \\
\hline & & & & \\
\hline Middle third & $0.93(0.79,1.09)$ & $0.87(0.69,1.10)$ & $0.99(0.90,1.09)$ & $0.99(0.86,1.13)$ \\
\hline Upper third & $1.03(0.87,1.22)$ & $1.07(0.84,1.37)$ & $0.98(0.89,1.07)$ & $0.94(0.81,1.08)$ \\
\hline \multicolumn{5}{|l|}{ Percent screening completed with FOBT (vs. lower third) } \\
\hline Middle third & $0.90(0.77,1.06)$ & $0.90(0.71,1.14)$ & $0.88(0.80,0.97)$ & $0.85(0.74,0.97)$ \\
\hline Upper third & $0.78(0.67,0.92)$ & $0.70(0.55,0.88)$ & $0.91(0.83,0.99)$ & $0.79(0.69,0.91)$ \\
\hline CR promotes FOBT over colonoscopy & $0.86(0.61,1.20)$ & $0.87(0.53,1.43)$ & $0.87(0.72,1.06)$ & $0.89(0.67,1.19)$ \\
\hline $\mathrm{CR}$ asks provider to enter elements of patient's family history & $1.08(0.82,1.41)$ & $1.14(0.77,1.68)$ & $0.92(0.79,1.07)$ & $0.98(0.77,1.23)$ \\
\hline CR can be turned off by provider & $0.91(0.76,1.09)$ & $0.99(0.76,1.29)$ & $0.97(0.87,1.08)$ & $0.83(0.71,0.97)$ \\
\hline CR allows provider to specify timing of next colonoscopy & $1.04(0.86,1.25)$ & $1.03(0.79,1.35)$ & $0.99(0.89,1.10)$ & $1.09(0.93,1.28)$ \\
\hline CR contains a general 'not indicated' option & $1.04(0.89,1.20)$ & $1.08(0.87,1.35)$ & $0.98(0.90,1.07)$ & $1.08(0.95,1.23)$ \\
\hline CR includes patient screening decision education & $0.86(0.71,1.04)$ & $0.79(0.60,1.05)$ & $1.03(0.92,1.15)$ & $0.88(0.75,1.04)$ \\
\hline \multicolumn{5}{|l|}{ CR completion assigned to (vs. intake nurse only): } \\
\hline Primary care provider only & $1.10(0.86,1.39)$ & $1.18(0.84,1.67)$ & $1.11(0.97,1.26)$ & $1.06(0.87,1.30)$ \\
\hline Both primary care provider and intake nurse & $1.10(0.88,1.37)$ & $1.13(0.82,1.56)$ & $1.16(1.02,1.31)$ & $1.08(0.90,1.31)$ \\
\hline \multicolumn{5}{|l|}{ COLONOSCOPY } \\
\hline \multicolumn{5}{|l|}{ Complexity score (vs. lower third) } \\
\hline Midd̂le third & $1.29(1.03,1.60)$ & $1.35(1.04,1.76)$ & $1.20(1.02,1.41)$ & \\
\hline Upper third & $1.09(0.87,1.37)$ & $1.01(0.78,1.32)$ & $1.37(1.17,1.61)$ & \\
\hline \multicolumn{5}{|l|}{ CRC screening performance score (vs. lower third) } \\
\hline Middle third & $1.23(0.99,1.52)$ & $1.23(0.95,1.60)$ & $1.13(0.97,1.32)$ & \\
\hline Upper third & $1.20(0.96,1.51)$ & $1.34(1.02,1.75)$ & $0.88(0.75,1.03)$ & \\
\hline \multicolumn{5}{|l|}{ Percent screening completed with FOBT (vs. lower third) } \\
\hline Middle third & $1.32(1.11,1.57)$ & $1.45(1.17,1.82)$ & $1.07(0.92,1.23)$ & \\
\hline Upper third & $2.20(1.84,2.62)$ & $2.34(1.87,2.93)$ & $1.47(1.27,1.71)$ & \\
\hline CR promotes FOBT over colonoscopy & $1.11(0.71,1.76)$ & $1.33(0.77,2.30)$ & $0.93(0.66,1.31)$ & \\
\hline CR asks provider to enter elements of patient's family history & $0.96(0.67,1.37)$ & $1.03(0.67,1.58)$ & $0.88(0.68,1.14)$ & \\
\hline CR can be turned off by provider & $1.06(0.83,1.35)$ & $1.18(0.88,1.58)$ & $0.89(0.74,1.06)$ & \\
\hline CR allows provider to specify timing of next colonoscopy & $0.81(0.63,1.04)$ & $0.81(0.60,1.10)$ & $0.90(0.75,1.08)$ & \\
\hline CR contains a general 'not indicated' option & $0.88(0.72,1.07)$ & $0.93(0.73,1.18)$ & $0.83(0.72,0.97)$ & \\
\hline & $1.19(0.92,1.55)$ & $1.20(0.88,1.65)$ & $1.14(0.94,1.39)$ & \\
\hline \multicolumn{5}{|l|}{ CR completion assigned to (vs. intake nurse only): } \\
\hline Primary care provider only & $0.73(0.53,0.99)$ & $0.70(0.48,1.02)$ & $0.85(0.67,1.06)$ & \\
\hline Both primary care provider and intake nurse & $0.74(0.55,0.99)$ & $0.69(0.48,0.97)$ & $0.95(0.76,1.18)$ & \\
\hline
\end{tabular}

CRC Colorectal cancer; CR Clinical reminder; FOBT Fecal occult blood test

* Odds ratio (95\% confidence interval) adjusted for clustering of patients within facilities, controlled for patient age, gender, race, ethnicity, and marital status

Healthcare systems have adopted a variety of strategies to promote screening in recent years. These strategies may powerfully influence rates of inappropriate screening either positively or negatively. Our study adds to the current research by identifying facility processes that correlate with potentially inappropriate screening and by comparing facilities that rely primarily on FOBT to those that use a more even mix of FOBT and colonoscopy. These analyses offer insight into how programs might be refined to minimize inappropriate screening. At the facilities where the highest proportion of screening was done with FOBT, the proportion of potentially inappropriate FOBTs was relatively small, but the proportion of potentially inappropriate screening colonoscopies was relatively large. Thus, healthcare systems may benefit from examining their processes to safeguard against inappropriate use of screening modes that are not the focus of their screening program. We also found that facilities where the primary care provider was assigned partial or full responsibility for completing the CRC clinical reminder were less likely to conduct potentially inappropriate colonoscopies, but were no less likely to conduct inappropriate FOBTs. We suspect that the reminder helps providers maintain appropriate intervals between colonoscopies and facilitates the identification of patients who are of limited life expectancy. Providers who do not interact with the reminder may use less effective processes to manage colonoscopy screening decisions.

Tests on older patients were more likely to be classified as potentially inappropriate across all reasons. As patients age, additional efforts to triage screening candidates may therefore be needed.

Our study has several limitations. First, our findings may not generalize to healthcare systems with screening rates that are lower than those of the VHA. It is noteworthy, however, that the Centers for Disease Control and Prevention have set a 2014 goal of achieving a nation-wide screening rate of $80 \%{ }^{32}$ Our findings may become increasingly relevant as provider organizations strive to meet this goal. Second, our classification of tests as potentially inappropriate is subject to error. A 
definitive determination of appropriateness requires a thorough review of each patient's individual circumstances. Third, there was some imprecision in the algorithm used to identify and exclude non-screening colonoscopies. This algorithm had high specificity but somewhat lower sensitivity, resulting in the exclusion of some screening colonoscopies. Nonetheless, the reliability of our algorithm was substantially higher than that reported in prior work using administrative data. ${ }^{27,28}$ Fourth, procedures and diagnoses obtained from non-VHA providers are not represented in our data set. Fifth, because we selected only one index test per patient, our results do not allow for the possibility that some patients may have been inappropriately screened multiple times. Because of these last three limitations, the rates of potentially inappropriate screening we report may be somewhat underestimated.

In spite of these limitations, our research demonstrates that, within the largest integrated healthcare system in the US, a substantial number of CRC screening tests may be inappropriate. Inappropriate screening may be partially addressed by establishing organizational processes that enforce appropriate screening intervals, triage patients with limited life expectancies, and discourage the use of FOBT to investigate gastroenterological symptoms.

Acknowledgements: The authors wish to thank Agnes Jensen (Center for Chronic Disease Outcomes Research, Minneapolis VA Health Care System) for her work conducting manual chart reviews. Research reported in this publication was supported by a Veterans Affairs Health Services Research and Development Career Development Award, CDA 08-024, granted to Dr. Powell, by the National Cancer Institute of the National Institutes of Health under Award Number R03CA166719, and by a Veterans Affairs Health Services Research and Development Research Career Scientist Award, RCS 10-185, granted to Dr. Partin. The content is solely the responsibility of the authors and does not necessarily represent the official views of the Department of Veterans Affairs or the National Institutes of Health. Study sponsors did not contribute to the design and conduct of the study; collection, management, analysis, interpretation of the data; preparation, review, or approval of the manuscript; or decision to submit the manuscript for publication.

Conflict of Interest: The authors declare that they have no conflicts of interest.

Corresponding Author: Adam A. Powell, PhD, MBA; Minneapolis VA Health Care System, One Veterans Drive, Building 9, Mail code 152, Minneapolis, MN 55417, USA (e-mail: apowell913@gmail.com).

\section{REFERENCES}

1. Siegel R, Desantis C, Jemal A. Colorectal cancer statistics, 2014. CA Cancer J Clin. 2014;64(2):104-117.

2. Pignone M, Rich M, Teutsch SM, Berg AO, Lohr KN. Screening for colorectal cancer in adults at average risk: A summary of the evidence for the US Preventive Services Task Force. Ann Intern Med. 2002;137(2):132141 .

3. Department of Veterans Affairs Veterans Health Administration. 2010 VHA facility quality and safety report. http://www.va.gov/health/docs/ HospitalReportCard2010.pdf. Accessed December 11, 2014.

4. Rim SH, Joseph DA, Steele CB, Thompson TD, Seeff LC. Centers for Disease Control and Prevention (CDC). Colorectal cancer screening United States, 2002, 2004, 2006, and 2008. Morb Mortal Wkly Rep Surveill Summ. 2011;60:42-46.
5. US Preventive Services. Task Force. Screening for colorectal cancer: US Preventive Services Task Force recommendation statement. Ann Intern Med. 2008; 149(9):627-637.

6. Zauber AG, Lansdorp-Vogelaar I, Knudsen AB, Wilschut J, van Ballegooijen M, Kuntz KM. Evaluating test strategies for colorectal cancer screening: A decision analysis for the US Preventive Services Task Force. Ann Intern Med. 2008;149(9):659-669.

7. Lee SJ, Boscardin WJ, Stijacic-Cenzer I, Conell-Price J, O'Brien S, Walter LC. Time lag to benefit after screening for breast and colorectal cancer: Meta-analysis of survival data from the United States, Sweden, United Kingdom, and Denmark. BMJ. 2013;346:e8441.

8. Levin B, Lieberman DA, McFarland B, et al. Screening and surveillance for the early detection of colorectal cancer and adenomatous polyps, 2008: A joint guideline from the American Cancer Society, the US Multi-society Task Force on Colorectal Cancer, and the American College of Radiology. Gastroenterology. 2008;134(5):1570-1595.

9. Whitlock EP, Lin JS, Liles E, Beil TL, Fu R. Screening for colorectal cancer: A targeted, updated systematic review for the US Preventive Services Task Force. Ann Intern Med. 2008;149(9):638-658.

10. Ko CW, Dominitz JA. Complications of colonoscopy: Magnitude and management. Gastrointest Endosc Clin N Am. 2010;20(4):659671.

11. Fisher DA, Judd L, Sanford NS. Inappropriate colorectal cancer screening: Findings and implications. Am J Gastroenterol. 2005; 100(11):2526-2530.

12. Ahmed FMD, Murthy UKMD. Inappropriate and improper use of fecal occult blood tests for colorectal cancer screening in the VA medical system. Am J Gastroenterol. 2006;101(6):1401.

13. Sheffield KM, Han Y, Kuo Y, Riall TS, Goodwin JS. Potentially inappropriate screening colonoscopy in Medicare patients: Variation by physician and geographic region. JAMA Intern Med. 2013;173(7):542-550.

14. Goodwin JS, Singh A, Reddy N, Riall TS, Kuo YF. Overuse of screening colonoscopy in the Medicare population. Arch Intern Med. 2011;171(15):1335-1343.

15. Partin MR, Powell AA, Bangerter A, et al. Levels and variation in overuse of fecal occult blood testing in the Veterans Health Administration. J Gen Intern Med. 2012;27(12):1618-1625.

16. Charlson ME, Pompei P, Ales KL, MacKenzie CR. A new method of classifying prognostic comorbidity in longitudinal studies: Development and validation. J Chronic Dis. 1987;40(5):373-383.

17. Deyo RA, Cherkin DC, Ciol MA. Adapting a clinical comorbidity index for use with ICD-9-CM administrative databases. J Clin Epidemiol. 1992;45(6):613-619.

18. Iversen LH, Norgaard M, Jacobsen J, Laurberg S, Sorensen HT. The impact of comorbidity on survival of Danish colorectal cancer patients from 1995 to 2006: A population-based cohort study. Dis Colon Rectum. 2009;52(1):71-78.

19. Cho H, Klabunde CN, Yabroff KR, et al. Comorbidity-adjusted life expectancy: A new tool to inform recommendations for optimal screening strategies. Ann Intern Med. 2013;159(10):667-676.

20. Walter LC, Bertenthal D, Lindquist K, Konety BR. PSA screening among elderly men with limited life expectancies. JAMA. 2006;296(19):23362342.

21. Walter LC, Lindquist $\mathbf{K}$, Nugent $\mathbf{S}$, et al. Impact of age and comorbidity on colorectal cancer screening among older veterans. Ann Intern Med. 2009; 150(7):465-473.

22. US preventive services task force: Screening for colorectal cancer. http:// www.uspreventiveservicestaskforce.org/uspstf/uspscolo.htm. Accessed December 11, 2014.

23. Ioannou GN, Chapko MK, Dominitz JA. Predictors of colorectal cancer screening participation in the United States. Am J Gastroenterol. 2003;98(9):2082-2091.

24. Meissner HI, Breen N, Klabunde CN, Vernon Sw. Patterns of colorectal cancer screening uptake among men and women in the United States. Cancer Epidemiol Biomarkers Prev. 2006;15(2):389394.

25. Partin M, Noorbaloochi S, Grill J, et al. The interrelationships between and contributions of background, cognitive, and environmental factors to colorectal cancer screening adherence. Cancer Causes and Control. 2010;21(9):1357-1368.

26. Stefos T, LaVallee N, Holden F. Fairness in prospective payment: A clustering approach. Health Serv Res. 1992;27(2):239.

27. Fisher DA, Jeffreys A, Coffman CJ, Fasanella K. Barriers to full colon evaluation for a positive fecal occult blood test. Cancer Epidemiol Biomarkers Prev. 2006;15(6):1232-1235. 
28. Etzioni DA, Yano EM, Rubenstein LV, et al. Measuring the quality of colorectal cancer screening: The importance of follow-up. Dis Colon Rectum. 2006;49(7):1002-1010.

29. Burnand B, Harris JK, Wietlisbach V, Froehlich F, Vader JP, Gonvers JJ. Use, appropriateness, and diagnostic yield of screening colonoscopy: An international observational study (EPAGE). Gastrointest Endosc. 2006;63(7):1018-1026.

30. Baron TH, Kimery BD, Sorbi D, Gorkis LC, Leighton JA, Fleischer DE. Strategies to address increased demand for colonoscopy: Guidelines in an open endoscopy practice. Clin Gastroenterol Hepatol. 2004;2(2):178-182.

31. Mahajan RJ, Barthel JS, Marshall JB. Appropriateness of referrals for open-access endoscopy: How do physicians in different medical specialties do? Arch Intern Med. 1996;156(18):2065-2069.

32. Centers for Disease Control and Prevention. Vital signs: colorectal cancer screening test use-United States, 2012. MMWR Morb Mortal Wkly Rep. 2013;62(44):881-888.

\section{APPENDIX 1}

Table 6. Gastrointestinal Conditions Used to Assess Whether FOBT Cases Indicated for Colonoscopy Instead (Potentially Inappropriate - Wrong Test Classification)

\begin{tabular}{lll}
\hline \hline ICD 9 codes & Diagnosis & Time interval \\
\hline 2851,2859 & Anemia & Within 30 days \\
56985 & Angiodysplasia w hem & Within 30 days \\
7830 & Anorexia & Within 30 days \\
5609 & Bowel Obstruction & Within 30 days \\
56212 & Diverticulitis w hem & Within 30 days \\
56213 & Diverticulosis w hem & Within 30 days \\
578 & GI Bleed & Within 30 days \\
5693 & Hemorrhage Rectum & Within 30 days \\
& Anus & \\
5600 & Intussusception & Within 30 days \\
280 & Iron-Deficiency Anemia & Within 30 days \\
5641 & Irritable Colon & Within 30 days \\
5647 & Megacolon & Within 30 days \\
5601 & Paralytic Ileus & Within 30 days \\
555 & Crohn Disease & Within 10 years \\
556,5581 & Ulcerative Colitis & Within 10 years \\
$153,1540,1541,1548$, & Personal History of & Within 10 years \\
$2303,2304,2307$, & Colorectal Cancer & \\
V1005, V1006 & Family History of & Within 10 years \\
Designation varies & Colorectal Cancer & \\
by facility & Heme-positive Stool with & Within 10 years \\
7921 & no documentation of & \\
& follow-up colonoscopy & \\
\hline & & \\
\hline & &
\end{tabular}

\section{APPENDIX 2. IDENTIFICATION OF SCREENING COLONOSCOPIES}

Step 1. All colonoscopy cases in which one or more of the diagnostic codes listed below had been entered into the medical record between 0 and 365 days of the target test date were classified as NON-SCREENING.

\begin{tabular}{|c|c|}
\hline ICD-9 codes & Diagnosis \\
\hline 7873 & Abdominal Distention \\
\hline 7890 & Abdominal Pain \\
\hline 7893 & Abdominal Swelling \\
\hline 2851,2859 & Anemia \\
\hline 56985 & Angiodysplasia w hem \\
\hline 7830 & Anorexia \\
\hline 5609 & Bowel Obstruction \\
\hline 7879 & Change Bowel Habits \\
\hline 5581 & Colitis-Radiation \\
\hline 5640 & Constipation \\
\hline 555 & Crohn Disease \\
\hline 5589,5645 & Diarrhea \\
\hline 56212 & Diverticulitis w hem \\
\hline 56213 & Diverticulosis w hem \\
\hline 7876 & Fecal Incontinence \\
\hline 578 & GI Bleed \\
\hline Designation varies by facility & Heme-positive Stool \\
\hline 5693 & Hemorrhage Rectum Anus \\
\hline 5600 & Intussusception \\
\hline 280 & Iron-Deficiency Anemia \\
\hline 5641 & Irritable Colon \\
\hline 5647 & Megacolon \\
\hline 7870 & Nausea Vomiting \\
\hline 5601 & Paralytic Ileus \\
\hline 556 & Ulcerative Colitis \\
\hline 7832 & Weight Loss \\
\hline $\begin{array}{c}153,1540,1541,1548,2303, \\
2304,2307, \text { V } 1005, \mathrm{~V} 1006\end{array}$ & $\begin{array}{l}\text { Personal History of Colorectal } \\
\text { Cancer }\end{array}$ \\
\hline V1851, V160 & $\begin{array}{l}\text { Family History of Colorectal } \\
\text { Cancer }\end{array}$ \\
\hline
\end{tabular}

Step 2. Of colonoscopy cases not classified as nonscreening in Step 1, the following variables were used to generate a model predicting the probability of the case being a non-screening colonoscopy. Cases with an estimated probability greater than $50 \%$ were classified as non-screening.

Presence/date of prior colonoscopy

Presence/date of prior FOBT

Prior FOBT result

Presence/date of prior barium enema

Target colonoscopy location (VHA or non-VHA facility)

Presence/date of benign neoplasm of rectum and anal canal code 211.4

Presence/date of Personal history of colonic polyps code V12.72

Presence/date of benign neoplasm of colon code 211.3

Patient age

Patient service connected status (presence of disability designation)

Charlson comorbidity index

Primary care provider panel size

Facility complexity score 


\section{APPENDIX 3}

Table 7. Percent of Screened Patients Who Were Classified as Having Received Potentially Inappropriate Screening Test by Type of Inappropriate Screening and Patient Characteristics

\begin{tabular}{|c|c|c|c|c|c|c|c|c|c|}
\hline & \multicolumn{5}{|l|}{ FOBT } & \multicolumn{4}{|c|}{ Screening Colonoscopy } \\
\hline & $\mathbf{N}$ & $\begin{array}{l}\text { Any } \\
\text { Reason }\end{array}$ & $\begin{array}{l}\text { Not } \\
\text { Due }\end{array}$ & $\begin{array}{l}\text { Limited Life } \\
\text { Expectancy }\end{array}$ & $\begin{array}{l}\text { Wrong } \\
\text { Test }\end{array}$ & $\mathbf{N}$ & $\begin{array}{l}\text { Any } \\
\text { Reason }\end{array}$ & $\begin{array}{l}\text { Not } \\
\text { Due }\end{array}$ & $\begin{array}{l}\text { Limited Life } \\
\text { Expectancy }\end{array}$ \\
\hline \multicolumn{10}{|l|}{ Age in years } \\
\hline Under 65 & 535,686 & $20.4 \%$ & $11.4 \%$ & $4.5 \%$ & $8.4 \%$ & 102,669 & $12.8 \%$ & $9.5 \%$ & $3.7 \%$ \\
\hline $\begin{array}{l}65 \text { and Older } \\
\text { Gender }\end{array}$ & 365,606 & $34.4 \%$ & $17.6 \%$ & $12.6 \%$ & $14.7 \%$ & 31,666 & $18.9 \%$ & $13.3 \%$ & $6.5 \%$ \\
\hline Female & 44,173 & $25.4 \%$ & $15.0 \%$ & $4.7 \%$ & $11.9 \%$ & 6,291 & $11.3 \%$ & $9.0 \%$ & $2.5 \%$ \\
\hline Male & 857,118 & $26.1 \%$ & $13.9 \%$ & $8.0 \%$ & $10.9 \%$ & 128,044 & $14.4 \%$ & $10.4 \%$ & $4.5 \%$ \\
\hline \multicolumn{10}{|l|}{ Race } \\
\hline White & 651,549 & $26.4 \%$ & $14.3 \%$ & $7.9 \%$ & $11.1 \%$ & 92,610 & $14.3 \%$ & $10.6 \%$ & $4.2 \%$ \\
\hline African American & 137,465 & $27.6 \%$ & $14.3 \%$ & $8.7 \%$ & $11.9 \%$ & 24,073 & $15.1 \%$ & $9.7 \%$ & $6.2 \%$ \\
\hline $\begin{array}{l}\text { American Indian/ } \\
\text { Alaskan Native }\end{array}$ & 13,126 & $27.0 \%$ & $15.1 \%$ & $7.6 \%$ & $10.5 \%$ & 2,299 & $13.7 \%$ & $9.9 \%$ & $4.3 \%$ \\
\hline $\begin{array}{l}\text { Asian/Pacific Island } \\
\text { Ethnicity }\end{array}$ & 4,674 & $26.1 \%$ & $14.5 \%$ & $6.9 \%$ & $10.2 \%$ & 870 & $11.5 \%$ & $9.3 \%$ & $2.3 \%$ \\
\hline Non-Hispanic/Latino & 753,129 & $26.5 \%$ & $14.4 \%$ & $8.0 \%$ & $11.1 \%$ & 114,490 & $14.4 \%$ & $10.4 \%$ & $4.5 \%$ \\
\hline $\begin{array}{l}\text { Hispanic/Latino } \\
\text { Marital Status }\end{array}$ & 55,426 & $26.7 \%$ & $12.7 \%$ & $8.5 \%$ & $11.3 \%$ & 7,212 & $15.6 \%$ & $10.7 \%$ & $5.5 \%$ \\
\hline Married & 502,800 & $26.6 \%$ & $14.2 \%$ & $7.8 \%$ & $11.3 \%$ & 70,189 & $14.1 \%$ & $10.7 \%$ & $3.9 \%$ \\
\hline $\begin{array}{l}\text { Single Never } \\
\text { Married }\end{array}$ & 80,177 & $23.4 \%$ & $12.2 \%$ & $6.9 \%$ & $9.7 \%$ & 14,108 & $13.9 \%$ & $9.2 \%$ & $5.1 \%$ \\
\hline Divorced/Separated & 265,697 & $24.0 \%$ & $13.5 \%$ & $6.3 \%$ & $9.8 \%$ & 44,675 & $14.1 \%$ & $10.1 \%$ & $4.6 \%$ \\
\hline Widowed & 50,412 & $37.1 \%$ & $16.7 \%$ & $17.3 \%$ & $16.2 \%$ & 5,061 & $18.4 \%$ & $12.2 \%$ & $7.1 \%$ \\
\hline
\end{tabular}




\section{APPENDIX 4}

Table 8. Percent of Screened Patients Who Were Classified as Having Received Potentially Inappropriate Screening Test by Type of Inappropriate Screening and Facility Characteristics

\begin{tabular}{|c|c|c|c|c|c|c|c|c|c|}
\hline & \multicolumn{5}{|l|}{ FOBT } & \multicolumn{4}{|c|}{ Screening Colonoscopy } \\
\hline & $\mathbf{N}$ & $\begin{array}{l}\text { Any } \\
\text { Reason }\end{array}$ & $\begin{array}{l}\text { Not } \\
\text { Due }\end{array}$ & $\begin{array}{l}\text { Limited Life } \\
\text { Expectancy }\end{array}$ & $\begin{array}{l}\text { Wrong } \\
\text { Test }\end{array}$ & $\mathbf{N}$ & $\begin{array}{l}\text { Any } \\
\text { Reason }\end{array}$ & $\begin{array}{l}\text { Not } \\
\text { Due }\end{array}$ & $\begin{array}{l}\text { Limited Life } \\
\text { Expectancy }\end{array}$ \\
\hline \multicolumn{10}{|c|}{ Standardized Complexity Score } \\
\hline Lower third & 157,141 & $26.2 \%$ & $14.6 \%$ & $7.4 \%$ & $11.0 \%$ & 23,909 & $12.5 \%$ & $9.4 \%$ & $3.4 \%$ \\
\hline Middle third & 353,991 & $28.1 \%$ & $15.9 \%$ & $8.1 \%$ & $11.5 \%$ & 46,345 & $15.8 \%$ & $12.2 \%$ & $4.2 \%$ \\
\hline Upper third & 388,211 & $24.1 \%$ & $11.8 \%$ & $7.7 \%$ & $10.5 \%$ & 64,032 & $13.7 \%$ & $9.4 \%$ & $4.8 \%$ \\
\hline \multicolumn{10}{|c|}{ CRC Screening Performance Score (Range 71 to $93 \%$ ) } \\
\hline$<80 \%$ & 298,795 & $25.0 \%$ & $13.1 \%$ & $7.3 \%$ & $10.7 \%$ & 44,385 & $12.6 \%$ & $8.6 \%$ & $4.3 \%$ \\
\hline 80 to $84 \%$ & 314,893 & $26.2 \%$ & $13.4 \%$ & $8.0 \%$ & $11.6 \%$ & 41,847 & $15.0 \%$ & $10.7 \%$ & $4.9 \%$ \\
\hline$>84 \%$ & 286,508 & $27.1 \%$ & $15.4 \%$ & $8.0 \%$ & $10.6 \%$ & 48,092 & $15.1 \%$ & $11.6 \%$ & $4.0 \%$ \\
\hline \multicolumn{10}{|c|}{ Percent screening completed with FOBT (Range 18.6 to $99.6 \%$ ) } \\
\hline$<82 \%$ & 145,302 & $28.4 \%$ & $15.8 \%$ & $9.2 \%$ & $12.2 \%$ & 63,217 & $12.0 \%$ & $8.5 \%$ & $3.9 \%$ \\
\hline 82 to $91 \%$ & 357,324 & $26.7 \%$ & $15.0 \%$ & $7.4 \%$ & $11.1 \%$ & 51,238 & $14.3 \%$ & $10.5 \%$ & $4.3 \%$ \\
\hline$>91 \%$ & 398,666 & $24.7 \%$ & $12.3 \%$ & $7.7 \%$ & $10.4 \%$ & 19,880 & $20.9 \%$ & $16.0 \%$ & $5.8 \%$ \\
\hline \multicolumn{10}{|c|}{ CR completion instructions promote: } \\
\hline $\begin{array}{l}\text { Colonoscopy over } \\
\text { FOBT }\end{array}$ & 26,051 & $28.5 \%$ & $17.2 \%$ & $8.4 \%$ & $10.2 \%$ & 7,859 & $10.3 \%$ & $7.2 \%$ & $3.5 \%$ \\
\hline $\begin{array}{l}\text { FOBT over } \\
\text { colonoscopy }\end{array}$ & 257,004 & $27.8 \%$ & $15.9 \%$ & $8.0 \%$ & $11.2 \%$ & 32,750 & $15.6 \%$ & $11.9 \%$ & $4.2 \%$ \\
\hline \multicolumn{10}{|c|}{ CR asks provider to enter elements of patient's family history } \\
\hline No & 686,825 & $26.4 \%$ & $14.3 \%$ & $7.8 \%$ & $11.0 \%$ & 102,988 & $14.5 \%$ & $10.6 \%$ & $4.4 \%$ \\
\hline Yes & 74,752 & $27.0 \%$ & $15.7 \%$ & $7.2 \%$ & $10.7 \%$ & 9,579 & $13.7 \%$ & $10.1 \%$ & $4.1 \%$ \\
\hline \multicolumn{10}{|c|}{ CR can be turned off by provider } \\
\hline No & 600,734 & $26.7 \%$ & $14.3 \%$ & $7.9 \%$ & $11.3 \%$ & 85,608 & $14.2 \%$ & $10.2 \%$ & $4.5 \%$ \\
\hline Yes & 160,843 & $25.5 \%$ & $15.2 \%$ & $7.3 \%$ & $9.5 \%$ & 26,959 & $15.2 \%$ & $11.7 \%$ & $4.1 \%$ \\
\hline \multicolumn{10}{|c|}{ CR allows provider to specify timing of next colonoscopy } \\
\hline No & 626,277 & $26.1 \%$ & $14.2 \%$ & $7.7 \%$ & $10.7 \%$ & 87,339 & $14.5 \%$ & $10.5 \%$ & $4.5 \%$ \\
\hline Yes & 108,359 & $29.1 \%$ & $17.6 \%$ & $8.3 \%$ & $11.3 \%$ & 24,375 & $13.7 \%$ & $10.2 \%$ & $4.1 \%$ \\
\hline \multicolumn{10}{|c|}{ CR contains a general 'not indicated' option (no further input required) } \\
\hline No & 466,453 & $25.9 \%$ & $13.4 \%$ & $7.8 \%$ & $11.0 \%$ & 57,236 & $14.8 \%$ & $10.6 \%$ & $4.8 \%$ \\
\hline Yes & 295,124 & $27.4 \%$ & $16.1 \%$ & $7.8 \%$ & $10.9 \%$ & 55,331 & $14.1 \%$ & $10.5 \%$ & $4.0 \%$ \\
\hline \multicolumn{10}{|c|}{$\mathrm{CR}$ includes patient screening decision education } \\
\hline No & 618,427 & $27.2 \%$ & $15.1 \%$ & $7.9 \%$ & $11.2 \%$ & 99,462 & $14.3 \%$ & $10.5 \%$ & $4.3 \%$ \\
\hline Yes & 143,150 & $23.2 \%$ & $11.8 \%$ & $7.1 \%$ & $9.7 \%$ & 13,105 & $15.6 \%$ & $11.1 \%$ & $5.0 \%$ \\
\hline \multicolumn{10}{|c|}{ CR completion assigned to: } \\
\hline Intake Nurse Only & 219,691 & $25.6 \%$ & $13.3 \%$ & $7.1 \%$ & $11.2 \%$ & 21,032 & $17.2 \%$ & $13.1 \%$ & $4.7 \%$ \\
\hline $\begin{array}{l}\text { Primary Care } \\
\text { Provider Only }\end{array}$ & 154,841 & $28.1 \%$ & $15.4 \%$ & $8.5 \%$ & $11.6 \%$ & 24,891 & $14.0 \%$ & $10.1 \%$ & $4.4 \%$ \\
\hline $\begin{array}{l}\text { Both Primary Care } \\
\text { Provider \& Nurse }\end{array}$ & 207,004 & $25.3 \%$ & $14.2 \%$ & $7.7 \%$ & $10.1 \%$ & 35,231 & $15.0 \%$ & $11.1 \%$ & $4.5 \%$ \\
\hline
\end{tabular}

